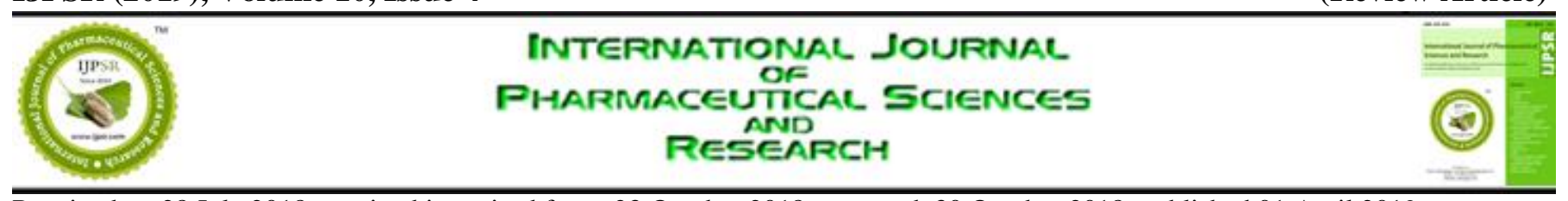

Received on 28 July 2018; received in revised form, 23 October 2018; accepted, 30 October 2018; published 01 April 2019

\title{
BIOLOGICAL ACTIVITIES OF FLAVONOIDS: AN OVERVIEW
}

\section{Prithviraj Karak}

Department of Physiology, Bankura Christian College, Bankura - 722101, West Bengal, India.

Keywords:

Phytonutrients, Flavonoids, Antioxidant, Cardioprotective, Anti-cancer

Correspondence to Author:

Dr. Prithviraj Karak

Assistant Professor, Department of Physiology, Bankura Christian College, Bankura - 722101, West Bengal, India.

E-mail: drpkarak@gmail.com
ABSTRACT: Background: Plants and herbs consumed by humans are the rich sources of phytonutrients compounds synthesized in plants itself. Such bioactive substances are responsible for the plant's antioxidant and medicinal values. Flavonoids are an essential group of naturally occurring polyphenolic compounds, and its flavan nucleus characterizes it. It is one of the most common classes of compounds available in vegetables, fruits, and plant-derived beverages. Flavonoids are considered as health promoting and disease preventing dietary supplements. It is now considered as an indispensable component in a variety of nutraceutical, pharmaceutical, medicinal, cosmetic and other applications. Objectives: The main aim of this present review is to discuss the current trends of research and development on flavonoids, general working mechanisms of flavonoids, functions, and applications of flavonoids, prediction of flavonoids as potential drugs in preventing many chronic diseases and future research directions. Discussion: Their basic structures consist of C6-C3-C6 rings with different substitution patterns to produce a series of subclass compounds such as flavones, flavonols, flavanones, isoflavones, flavanols or catechins and anthocyanins. Many flavonoid compounds are shown to have an antioxidative activity, free radical scavenging capacity, cardioprotective, antidiabetic, anti-inflammatory, anti-allergic while some other flavonoid compounds exhibit potential antiviral activities. More recently flavonoids are proven to be the most effective as an anti-cancer agent, through apoptosis by induction of cell cycle arrest and inhibition of key enzymes involved in tumor promotion.
INTRODUCTION: Polyphenols are chemical compounds of the secondary plant metabolism that can accumulate in specific group of plant organs such as leaves, fruits, roots, and stems. As a large group of bioactive chemicals, they have diverse biological functions. Flavonoids are phenolic substances widely distributed in all vascular plants.

\begin{tabular}{|l|c|}
\hline QUICK RESPONSE CODE & DOI: \\
\hline DOI link: http://dx.doi.org/10.13040/IJPSR.0975-8232.10(4).1567-74 \\
\cline { 2 - 3 }
\end{tabular}

They are a diverse group of phytonutrients (plant chemicals) ubiquitous in many fruits, vegetables and medicinal plants in which they occur as the free forms, glycosides, as well as methylated derivatives.

Flavonoids are the low molecular weight compound ${ }^{1,2}$ bioactive polyphenols ${ }^{3}$ which play an essential role in photosynthesizing cells ${ }^{4}$. The original "flavonoid" research started in 1936, when Hungarian scientist Albert Szent-Gyorgi was uncovering a synergy between pure vitamin $\mathrm{C}$ and as yet unidentified cofactors from the peels of lemons, which he first called "citrin," and later it referred to as "vitamin $\mathrm{P}{ }^{5}$. 
They display an extensive range of structures, and they are responsible for the significant organoleptic characteristics of plant-derived foods and beverages, particularly color and taste properties. They also contribute to the nutritional qualities of fruits and vegetables.

Flavonoids are hydroxylated phenolic substances and are synthesized by plants in response to microbial infection ${ }^{6}$. Flavonoids are a subdivision of a large group of polyphenolic compounds having a benzo- $\gamma$-pyrone structure, a versatile class of natural compounds that represent secondary metabolites. Flavonoids have aroused enormous interest in the preceding decade because of their multidimensional health effects on human and animal health, and omnipresence in the plant kingdom. They are called "functional ingredients" and "health promoting biomolecules" in recent literature due to their potential role in promoting health and preventing chronic degenerative diseases ${ }^{7}$. They have played significant roles in successful medical treatments in ancient as well as modern times.

Flavanoids having several biochemical and antioxidant effects associated with various diseases such as cancer, Alzheimer's disease (AD), atherosclerosis, etc. ${ }^{8-10}$ Flavonoids are associated with a broad spectrum of health-promoting effects and are an indispensable component in a variety of nutraceutical, pharmaceutical, medicinal and cosmetic applications. This is because of their potent anti-oxidative, anti-inflammatory, antimutagenic, antimicrobial, anti-carcinogenic, vascular activities, free radical scavenging abilities, and other medicinal properties coupled with their capacity to modulate essential cellular enzyme functions. They are also known to be potent inhibitors for several enzymes, such as aldose reductase, $\mathrm{Ca}^{2+}$ - ATPase, xanthine oxidase (XO), cyclo-oxygenase (COX), lipoxygenase and phosphoinositide 3-kinase ${ }^{11-13}$.

The antimicrobial properties of flavonoids were proposed for both the development of new food preservatives and development of therapies. It is used for the treatment of various microbial infections, considering the increase in microbial resistance against antibiotic treatment. Nowadays, about $70 \%$ of the bacteria that cause infections in hospitals are resistant to at least one of the drugs most commonly used for treatment. Some organisms are immune to all approved antibiotics and can only are treated with experimental and potentially toxic drugs.

The main aim of this review was to highlights the overview of the research in the field of flavonoids. The potential valuable physiological and antimicrobial actions of flavonoids are discussed. In the last part of this review article, the critical clinical applications of flavonoids in human body system were discussed.

Chemistry of Flavonoid: Flavonoids are part of the polyphenol class of phytonutrients. Polyphenols have historically been used in Chinese and Ayurvedic medicine. According to the Global Healing Center, they are associated with skin protection, brain function, blood sugar, and blood pressure regulation, in addition to antioxidant and anti-inflammatory activity. In 1930 a new substance was isolated from oranges. At that time it was believed to be a member of a new class of vitamins and was designated as vitamin P. Later on it became clear that this substance was a flavonoid (rutin) and till now more than 4000 varieties of flavonoids have been identified ${ }^{14}$.

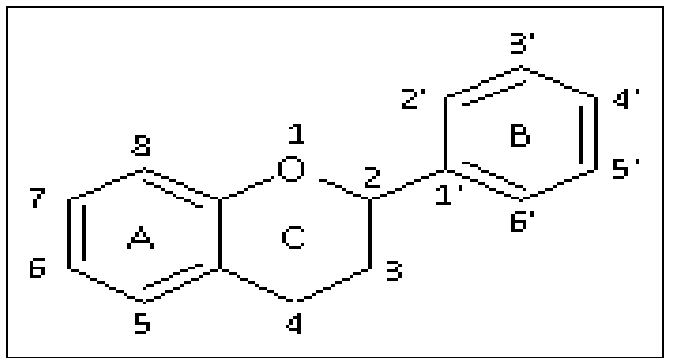

FIG. 1: BASIC STRUCTURE OF FLAVONOID

Flavonoids occur as aglycones, glycosides and methylated derivatives 15 . In plants, flavonoids aglycones (i.e., flavonoids without attached sugar) occur in a variety of structural forms. The basic chemical structure of flavonoid is a skeleton of diphenyl propane, contain fifteen carbon atoms in their primary nucleus: two six-membered rings linked with a three carbon unit which may or may not be a part of a third ring ${ }^{16}$. Mainly two benzene rings (ring $\mathrm{A}$ and $\mathrm{B}$ ) are linked together through third heterocyclic oxygen-containing pyrene ring ${ }^{17}$. So, this structure is also referred to as C6-C3-C6 labeled A, B, and $\mathrm{C}^{18-19}$ Fig. 1. 
Flavonoids can be subdivided into different subgroups depending on the carbon of the $\mathrm{C}$ ring on which $\mathrm{B}$ ring is attached and the degree of unsaturation and oxidation of the $\mathrm{C}$ ring ${ }^{20}$. Flavonoids in which $\mathrm{B}$ ring is linked in position 3 of the ring $\mathrm{C}$ are called isoflavones; those in which $\mathrm{B}$ ring is linked in position 4, neoflavonoids, while those in which the B ring is linked in position 2 can be further subdivided into several subgroups on the basis of the structural features of the $\mathrm{C}$ ring. This subgroup is flavones, flavonols, flavanones, flavanonols, flavanols or catechins, and anthocyanins ${ }^{21-22}$ Fig. 2. Finally, flavonoids with open $\mathrm{C}$ ring are called chalcones.

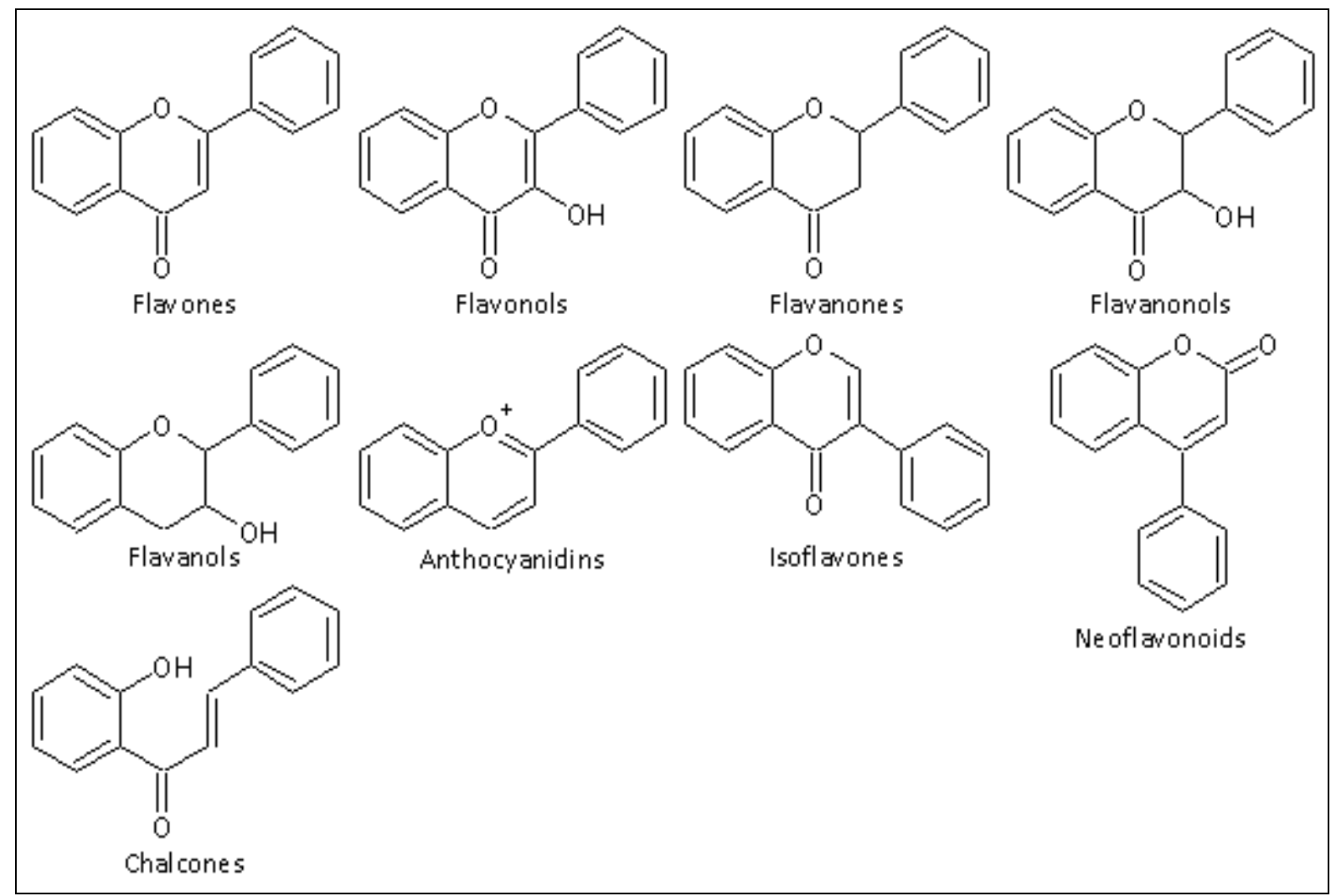

FIG. 2: DIFFERENT TYPES OF FLAVONOID AND THEIR CHEMICAL STRUCTURE

Some food sources containing different classes of flavonoids are given in Table 1. Being phytochemicals, flavonoids cannot be synthesized by humans and animals. Flavonoids are found in the highest amounts in the human diet include the soy isoflavones, flavonols, and the flavones. Table 2 summarizes some of the medicinal plants rich in flavonoid contents.

TABLE 1: SUBCLASSES OF FLAVONOIDS AND THEIR OCCURRENCE IN FOODS ${ }^{23-25}$

\begin{tabular}{|c|c|c|c|c|}
\hline S. no. & Flavonoid subclass & Examples of compounds & Food source & References \\
\hline 1 & Flavonol & $\begin{array}{l}\text { Kaempferol, quercetin, } \\
\text { myricetin and tamarixetin }\end{array}$ & $\begin{array}{l}\text { Onion, red wine, kale, olive oil, broccoli } \\
\text { apples, cherries, berries, and grapefruit } \\
\text { and tea }\end{array}$ & 26 \\
\hline 3 & Flavonones & $\begin{array}{l}\text { Naringin, naringenin, taxifolin, } \\
\text { and hesperidin }\end{array}$ & $\begin{array}{c}\text { Citrus fruits, grapefruits, lemons, and } \\
\text { oranges }\end{array}$ & $31-32$ \\
\hline 4 & Flavanol & $\begin{array}{l}\text { Catechin, epicatechin, } \\
\text { epigallocatechin, glausan-3- } \\
\text { epicatechin, proanthocyanidins }\end{array}$ & Apple, tea & 26 \\
\hline 5 & Anthocyanidins & $\begin{array}{l}\text { Apigenidin, cyaniding, } \\
\text { delphinidin, pelargonidin, } \\
\text { malvidin }\end{array}$ & $\begin{array}{c}\text { Cherries, easberry, strawberry, and } \\
\text { Grapes }\end{array}$ & $26 \& 30$ \\
\hline
\end{tabular}


TABLE 2: SOME COMMON MEDICINAL PLANTS RICH IN FLAVONOIDS

\begin{tabular}{ccc}
\hline Plant & Flavonoid & References \\
\hline Aloe vera & Luteolin & 35 \\
Bacopa moneirra & Luteolin & 35 \\
Acalypha indica & Kaempferol & 35 \\
& glycosides & \\
Azadirachta indica & Quercetin & 36 \\
Betula pendula & Quercetin & 37 \\
Butea monospermea & Genistein & 38 \\
Brysonima crassa & (+)-catechin & 39 \\
Cannabis sativa & Quercetin & 36 \\
Clitoria ternatea & Kaempferol-3- & 40 \\
Mimosa pudica & neohesperidoside & \\
Oroxylum indicum & Isoquercetin & 41 \\
Pongamia pinnata & Chrysin & 41 \\
\hline
\end{tabular}

Special Characteristics of Flavonoids: Flavonoids are one of the most essential nonnitrogenous plant pigments. It is responsible for flower coloration by producing yellow or red/blue pigmentation in shoots, leaves, buds, petals, and fruits. This pigmentation is to attract pollinators to the flowers. In some types of plants, flavonoids are involved in UV filtration, symbiotic nitrogen fixation and floral pigmentation.

Different studies on flavonoids by spectroscopy analysis have revealed that most flavones and flavonols exhibit two major absorption bands. The band I (320-385) nm represents the flavan B ring absorption, while Band II (250-285) nm corresponds to the flavan A ring absorption Fig. 3.

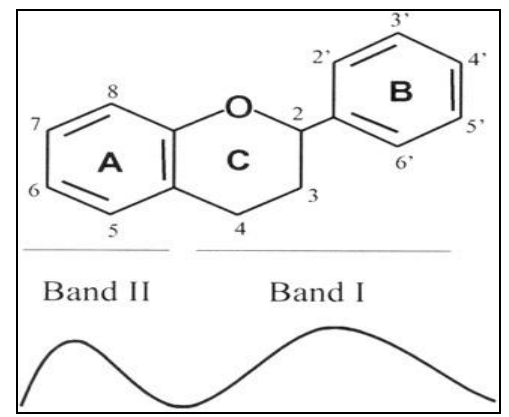

FIG. 3: DIFFERENT SPECTRUM OF SPECTROSCOPIC ABSORPTION OF FLAVAN NUCLEUS

Different functional groups attached to the flavonoid structure which may cause a shift in spectroscopic absorption from $367 \mathrm{~nm}$ in kaempferol $\left(3,5,7,4^{\prime}\right.$-hydroxyl groups) to $371 \mathrm{~nm}$ in quercetin $\left(3,5,7,3^{\prime}, 4^{\prime}\right.$-hydroxyl groups) and $374 \mathrm{~nm}$ in myricetin $\left(3,5,7,3^{\prime}, 4^{\prime}, 5^{\prime}\right.$-hydroxyl groups) ${ }^{43}$ Fig. 4. Flavanones also have a saturated heterocyclic $\mathrm{C}$ ring, with no conjugation between the $\mathrm{A}$ and $\mathrm{B}$ rings, as determined by their UV spectral characteristics $^{44}$.

Flavanones exhibit a very strong Band II absorption maximum range between 270 and $295 \mathrm{~nm}$, namely $288 \mathrm{~nm}$ (naringenin) and $285 \mathrm{~nm}$ (taxifolin) and only a shoulder for Band I at 326 and $327 \mathrm{~nm}$. Band II appears as one peak $(270 \mathrm{~nm})$ in compounds with a mono-substituted $\mathrm{B}$ ring, but as two peaks or one peak $(258 \mathrm{~nm})$ with a shoulder $(272 \mathrm{~nm})$ when a di-, tri-, or O-substituted $\mathrm{B}$ ring is present. As anthocyanins show distinctive B and I peak in the $450-560 \mathrm{~nm}$ region due to hydroxyl cinnamoyl system of the B ring and Band II peaks in the $240-280 \mathrm{~nm}$ region due to the benzoyl system of the A ring, the colour of the anthocyanins varies with the number and position of the hydroxyl groups 45 .

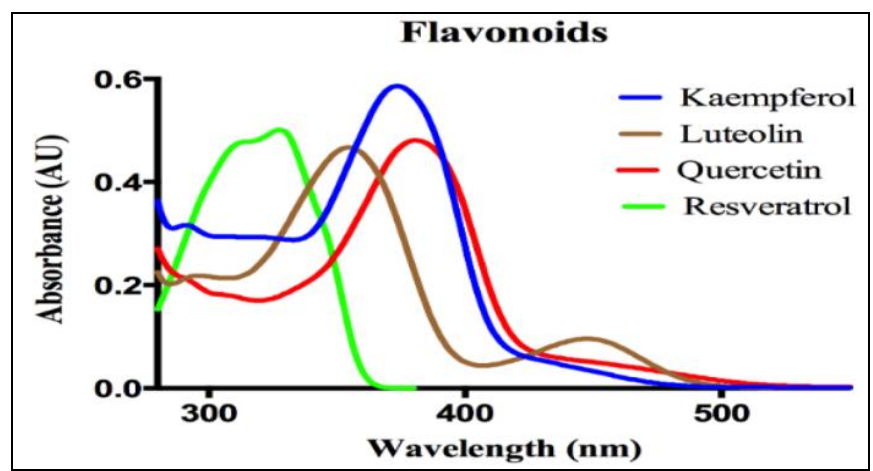

FIG. 4: UV SPECTRAL CHARACTERISTICS OF DIFFERENT FLAVONOIDS

Biological Activities of Flavonoids: Besides the main antioxidant property, flavonoids also possess many diverse biological activities that owe to the health aspects of human ${ }^{46-47}$. These activities are, for instance, anti-inflammatory, antiulcer, antiviral, anti-cancer, anti-diabetic and cytotoxic, etc.

Anti-oxidant Activity: Different studies have revealed broad nutritional effects of flavonoids to anti-oxidant activity. Most anti-oxidant chemical assays are showing to free radical scavenging mechanisms ${ }^{48}$. Antioxidants are reactive chemical compounds that protect human, animal and plant cells against the damaging effects of ROS. Flavonoids are one of the best phytochemicals that act as antioxidants and thus inhibit the factors of disease-causing. Antioxidant activity depends on the arrangement of functional groups in the flavan nucleus ${ }^{49-50}$. 
The configuration, substitution and total number of $-\mathrm{OH}$ groups substantially influence several mechanisms of antioxidant activity such as radical scavenging, activation of antioxidant enzymes ${ }^{51}$, reduction of $\alpha$-tocopheryl radicals ${ }^{52-53}$, inhibition of oxidases ${ }^{53-54}$, mitigation of oxidative stress caused by nitric oxide ${ }^{55}$, metal ion chelation ability 56 and increase in antioxidant properties of low molecular antioxidants ${ }^{57}$. The flavan nucleus B ring $-\mathrm{OH}$ configuration is the most significant determinant of scavenging of ROS and RNS because it donates hydrogen and an electron to hydroxyl, peroxyl and peroxynitrite radicals, stabilizing them and giving rise to a relatively stable flavonoids radical ${ }^{58}$. Flavonoids are also protecting the cell membranes which are damaged due to lipid peroxidation. Thus, the flavonoids contribute as antioxidants, in the prevention of many diseases caused due to oxidative stress ${ }^{59}$.

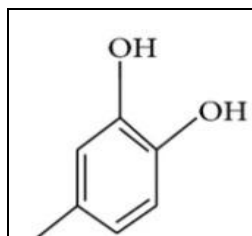

$\mathrm{Fl}-\mathrm{OH}$

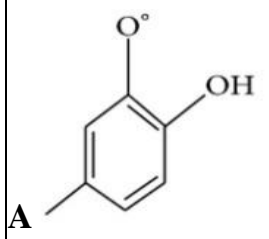

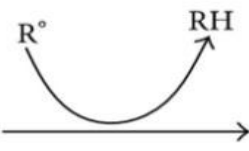

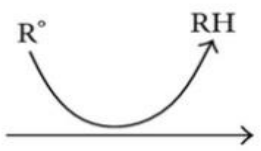

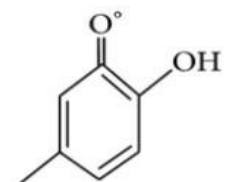

$\mathrm{F} 1-\mathrm{O}^{\circ}$

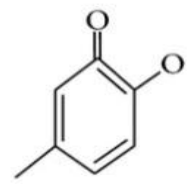

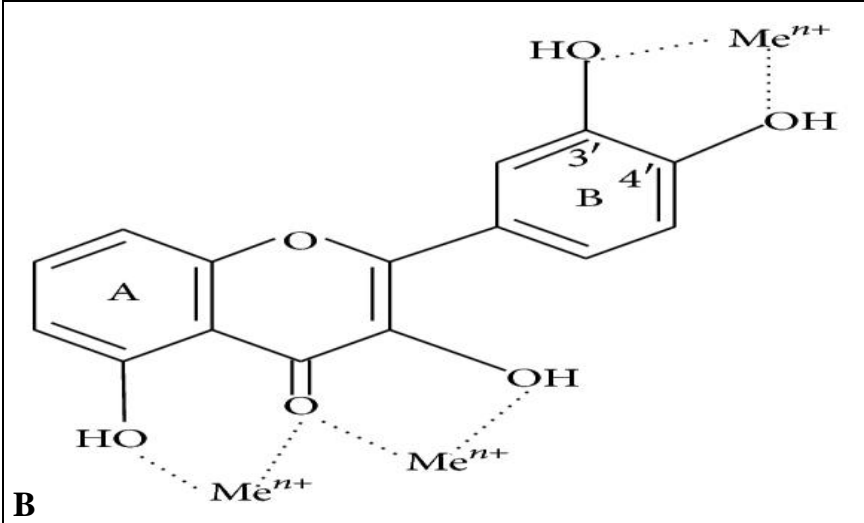

FIG. 5: (A) SCAVENGING OF ROS (R०) BY FLAVONOIDS (FI-OH); (B) BINDING SITES FOR TRACE METALS WHERE Me ${ }^{n^{+}}$INDICATES METAL IONS

Anti-Inflammatory Activity: Inflammation is a complex biological response of body tissues to harmful stimuli, such as pathogen infection, damaged cells, tissue injury, and chemical irritation. It is a protective response involving immune cells, blood vessels, and molecular mediators. This is initiated by the migration of immune cells from blood vessels and the release of chemical mediators at the site of tissue damage. Generally, the essential role of flavonoids on inflammation involved diseases such as leukemia, sepsis, asthma, sclerosis, atherosclerosis, psoriasis, allergic rhinitis, ileitis/ colitis, rheumatoid arthritis, etc. has been proposed. This process is followed by recruitment of inflammatory cells, the release of ROS, RNS, and proinflammatory cytokines to eliminate foreign pathogens and repair injured tissues. In general, normal inflammation is rapid and self-limiting, but the aberrant resolution and prolonged inflammation cause various chronic disorders ${ }^{60}$. Hesperidin, Luteolin and Quercetin are known to possess such type of anti-inflammatory property. They mainly affect the enzyme systems involved in the generation of inflammatory processes. Flavonoids also inhibit phospho-diesterases involved in cell activation.
Anti-Bacterial Activity: Plants can synthesize flavonoids in response to microbial infection and hence they are very effective antimicrobial substances against a wide variety of microorganisms. The different study shows the flavonoid-rich plant extracts from different plants possess antibacterial activity 61-64. Apigenin, galangin, flavone and flavonol glycosides, isoflavones, flavanones, and chalcones have been proved to possess potent antimicrobial activity ${ }^{65}$. The mode of antimicrobial action may be related to their ability to inactivate microbial adhesins, enzymes, cell envelope transport proteins, and so forth. Lipophilic flavonoids may also disrupt bacterial membranes ${ }^{66-67}$.

Antiviral Activity: Since the 1940s and many reports show that naturally occurring flavonoids exhibit a remarkable anti-viral activity. They help in the inhibition of various enzymes associated with the life cycle of viruses. The structural and functional relationship between flavonoids and their enzyme inhibitory activity has been observed. Flavon-3-ol was found to be more effective than flavones and flavonones in selective inhibition of HIV-1 \& HIV-2 and similar immunodeficiency 
virus causing infections ${ }^{68}$. The different study shows that quercetin, hesperetin, and naringin also possess anti-dengue activity ${ }^{69}$.

Anti-Cancer Activity: Cancer is a multistep disease incorporating physical, environmental, metabolic, chemical and genetic factors, which play an important role in the induction and deterioration of cancers. Many polyphenolic compounds such as flavonoids, phenolic acids, anthocyanidins, and tannins possess a broad spectrum of pharmacological activity including anti-cancer activities ${ }^{70-71}$. They have been reported to interfere in the initiation, promotion, and progression of cancer by modulating different enzymes and receptors in signal transduction pathways related to cellular proliferation, differentiation, apoptosis, inflammation, angiogenesis, metastasis and reversal of multidrug resistance.

Due to their multiple molecular mechanisms of action, flavonoids have been proved for their potential applications in anti-cancer therapies. Flavonoids greatly influence the cascade of immunological events associated with the development and progression of cancer. They have the potential of modulating many biological events in cancer such as apoptosis, vascularization, cell differentiation, cell proliferation, etc. A strong correlation persists between flavonoid-induced modulation of kinases with apoptosis, cell proliferation and tumor cell invasive behavior invitro. Flavonoids mainly stimulate the initiation and promotion stages of the carcinogenicity, along with influences on development and hormonal activity. They also act by cell-cycle arrest, downregulation of mutant $\mathrm{p} 53$ protein, inhibition of many cancer-triggering enzymes and expression of Ras proteins.

CONCLUSION: Prevention and cure of diseases by using phytochemicals compounds especially flavonoids are well known. Fruits and vegetables are natural sources of flavonoids. Flavonoids are such phytochemicals exhibit many biological properties which are beneficial for human health. They are rich sources of natural antioxidants in human diets. Flavonoids neutralize the harmful effects of free radicals in the best of ways and thus help in the prevention of many diseases. They interact with a great number of cellular targets such as anti-oxidant, free-radical scavenger activities and also the anti-inflammatory, antibacterial, antiviral, anti-aging and especially anti-cancer properties.

This review highlights the dietary sources and various important biological activities of flavonoids that attributes to their beneficial roles in human health. Their applications in industry are beyond the limit of nutraceuticals and drug candidate molecules.

ACKNOWLEDGEMENT: The authors would like to acknowledge the technical support provided by the members of the Physiology department.

CONFLICT OF INTEREST: The authors declare that they have no conflict of interests.

\section{REFERENCES:}

1. Fernandez SP, Wasowski C, Loscalzo LM, Granger RE, Johnston GAR, Paladini AC and Marder M: Central nervous system depressant action of flavonoid glycosides. European Journal of Pharmacology 2006; 539: 168-176.

2. Heim KE, Tagliaferro AR and Bobliya, DJ: Flavonoids antioxidants: Chemistry, metabolism and structure-activity relationships. The Journal of Nutritional Biochemistry 2002; 13: 572-584.

3. Hollman PCH and Katan MB: Dietary Flavonoids: Intake, Health Effects and Bioavailability. Food and Chemical Toxicology 1999; 37: 937-942.

4. Cushnie TPT and Lamb AJ: Antimicrobial activity of flavonoids. International Journal of Antimicrobial Agents 2005; 26: 343-356.

5. Murray MT: Quercetin: Nature's antihistamine. Better Nutrition 1998. NTP Technical Report (no.409) on the toxicology and carcinogenesis studies of quercetin in F344/N rats. NIH Publication No. 91-3140 (1991).U.S. Department of Health and Human Services, Public Health Service, National Toxicology Program, Research Triangle Park, NC.

6. Dixon RA, Dey PM and Lamb CJ: Phytoalexins: enzymology and molecular biology. Advances in Enzymology and Related Areas of Molecular Biology 1983; 55: 1-136.

7. Nijveldt RJ, van Nood E, van Hoorn DE, Boelens PG, van Norren K and van Leeuwen PA: Flavonoids: a review of probable mechanisms of action and potential applications. Am J Clin Nutr 2001; 74(4): 418-25.

8. Burak $M$ and Imen $Y$ : Flavonoids and their antioxidant properties. TurkiyeKlin Tip BilDerg 1999; 19: 296-304.

9. Ovando C, Hernandez D and Hernandez E: Chemical studies of anthocyanins: a review. Food Chem 2009; 113: 859-871.

10. Lee Y, Yuk D and Lee J: Epigallocatechin-3-gallate prevents lipopolysaccharide-induced elevation of $\beta$ amyloid generation and memory deficiency. Brain Res 2009; 1250: 164-174.

11. Metodiewa D, Kochman A and Karolczak S: Evidence for antiradical and antioxidant properties of four biologically active $N, N$, diethylaminoethyl ethers of flavanone oximes: 
a comparison with natural polyphenolic flavonoid (rutin) action. Biochem Mol Biol Int 1997; 41: 1067-1075.

12. Hayashi T, Sawa K and Kawasaki M: Inhibition of cow's milk xanthine oxidase by flavonoids. J Nat Prod 1988; 51: 345-348.

13. Walker E, Pacold $M$ and Perisic O: Structural determinations of phosphoinositide 3-kinase inhibition by wortmannin, LY294002, quercetin, myricetin, and staurosporine. Mol Cell 2000; 6: 909-919.

14. Middleton EJ: Effect of plant flavonoids on immune and inflammatory cell function. Advances in Experimental Medicine and Biology 1998; 439: 175-182.

15. Harborne JB: The flavonoids- Advances in Research Since 1980. ed 1. London: Chapman and Hall 1988.

16. Middleton E: The flavonoids. Trends Pharmacol Sci 1984; 5: 335-338.

17. Kuhnau J: The flavonoids. A class of semiessential food components: their role in human nutrition. World Rev Nutr Diet 1976; 24: 117-191.

18. Pietta P: Flavonoids as antioxidants. Journal of Natural Products 2000; 63: 1035-1042.

19. Rice-Evans CA, Miller NJ and Paganga G: Structureantioxidant activity relationships of flavonoids and phenolic acids. Free Rad Bio \& Med 1976; 20(7): 933-56.

20. Graf B, Milbury P and Blumberg J: Flavonols, Flavones, Flavanones, and Human Health: Epidemiological Evidence. Journal of Medicinal Food 2005; 8: 281-290.

21. He J and Giusti: Anthocyanins: Natural Colorants with Health-Promoting Properties. Annual Review of Food Science and Technology 2010; 1: 163-87.

22. Ignat I, Volf I and Popa V: A critical review of methods for characterization of polyphenolic compounds in fruits and vegetables. Food Chemistry 2011; 126: 1821-1835.

23. Hollman PCH and Katan MB: Dietary Flavonoids: Intake, Health Effects and Bioavailability. Food and Chemical Toxicology 1999; 37: 937-42.

24. Majewska M and Czeczot H: Flavonoids in prevention and therapy diseases. TerLeki 2009; 65(5): 369-77.

25. Ren W, Qiao Z, Wang H, Zhu L and Zhang L: Flavonoids: Promising Anticancer agents. Medicinal Research Reviews 2003; 23: 519-34.

26. Stewart AJ, Bozonnet S, Mullen W, Jenkins GI, Lean ME and Crozier A: Occurrence of flavonols in tomatoes and tomato-based products. Journal of Agricultural and Food Chemistry 2000; 48(7): 2663-2669.

27. Middleton EJ: Effect of plant flavonoids on immune and inflammatory cell function. Advances in Experimental Medicine and Biology 1998; 439: 175-182.

28. Lopez M, Martinez F, Del Valle C, Orte C and Miro M: Analysis of phenolic constituents of biological interest in red wines by high-performance liquid chromatography. Journal of Chromatography A 2001; 922(1-2): 359-63.

29. Hara Y, Luo SJ, Wickremasinghe RL and Yamanishi T: Special issue on tea. Food Reviews Inter 1995; 11: 371-42.

30. Kreft S, Knapp M and Kreft I: Extraction of rutin from buck wheat (Fagopyrum esculentum Moench) seeds and determination by capillary electrophoresis. Journal of Agricultural and Food Chemistry 1999; 47(11): 4649-52.

31. Miyake Y, Shimoi K, Kumazawa S, Yamamoto K, Kinae $\mathrm{N}$ and Osawa T: Identification and antioxidant activity of flavonoid metabolites in plasma and urine of eriocitrintreated rats. Journal of Agricultural and Food Chemistry 2000; 48(8): 3217-3224.

32. Rousseff RL, Martin SF and Youtsey CO: Quantitative survey of narirutin, naringin, hesperidin, and neohesperidin in citrus. Journal of Agricultural and Food Chemistry 1987; 35(6): 1027-1030.
33. Kaufman PB, Duke JA, Brielmann H, Boik J and Hoyt JE: A comparative survey of leguminous plants as sources of the isoflavones, genistein and daidzein: implications for human nutrition and health. J Altern Complement Med 1997; 3(1): 7-12.

34. Reinli K and Block G: Phytoestrogen content of foods: a compendium of literature values. Nutrition and Cancer 1996; 26(2): 123-48.

35. Lázaro ML: Distribution and biological activities of the flavonoid luteolin. Mini-Reviews in Medicinal Chemistry 2009; 9(1): 31-59.

36. Tripoli E, Guardia ML, Giammanco S, Majo DD and Giammanco M: Citrus flavonoids: molecular structure, biological activity and nutritional properties: a review. Food Chemistry 2007; 104(2): 466-479.

37. Gupta KK, Taneja SC, Dhar KL and Atal CK: Flavonoids of Andrographis paniculata. Phytochemistry 1983; 22(1): 314-315.

38. Murlidhar A, Babu KS, Sankar TR, Redenna P, Reddy GV and Latha J: Anti-inflammatory activity of flavonoid fraction isolated from stem bark of Butea monosperma (Lam): a mechanism based study. International Journal of Phytopharmacology 2010; 1: 124-132.

39. Aderogba MA, Ogundaini AO and Eloff JN: Isolation of two flavonoids from Bauhinia monandra leaves and their antioxidative effects. The African Journal of Traditional, Complementary and Alternative Medicines 2006; 3(4): 5965.

40. Sankaranarayanan S, Bama $\mathrm{P}$ and Ramachandran J: Ethnobotanical study of medicinal plants used by traditional users in Villupuram district of Tamil Nadu, India. Journal of Medicinal Plant Research 2010; 4(12): 1089-1101.

41. Sannomiya M, Fonseca VB and Silva MAD: Flavonoids and antiulcerogenic activity from Byrsonima crassa leaves extracts. Journal of Ethnopharmacology 2005; 97(1): 1-6.

42. Agarwal M and Kamal: Studies on flavonoid production using in-vitro cultures of Momordica charantia. Indian Journal of Biotechnology 2007; 6(2): 277-79.

43. Yao LH, Jiang YM and Shi J: Flavonoids in food and their health benefits. Plant Foods for Human Nutrition 2004; 59(3): 113-22.

44. Rice-Evans CA, Miller NJ and Paganga G: Structureantioxidant activity relationships of flavonoids and phenolic acids. Free Radical Biology and Medicine 1996; 20(7): 933-956.

45. Wollenweber $\mathrm{E}$ and Dietz VH: Occurrence and distribution of free flavonoid aglycones in plants. Phytochemistry 1981; 20(5): 869-932.

46. Vessal M, Hemmati M and Vasei M: Antidiabetic effects of quercetin in streptozocin-induced diabetic rats. Comp Biochem Physiol 2003; 135: 357-364.

47. Ghasemzadeh A and Jaafar HZE: Anticancer and antioxidant activities of young Malaysian ginger (Zingiber officinale Roscoe) varieties grown under different $\mathrm{CO}_{2}$ concentration. Jour. Med. Plant Res 1986; 5: 3247-3255.

48. Zhang J, Wu Y and Zhao X: Chemopreventive effect of flavonoids from Ougan (Citrus reticulata cv. Suavissima) fruit against cancer cell proliferation and migration. J Funct Foods 2014; 10: 511-519.

49. Kelly EH, Anthony RT and Dennis JB: Flavonoid antioxidants: Chemistry, metabolism and structure-activity relationships. Nutri. Biochem 2002; 13(10): 572-584.

50. Kukic J, Petrovic C and Niketic: Antioxidant activity of four endemic Stachys taxa. Biol Pharmaceut Bull 2006; 29: 725-729. 
51. Nijveldt RJ, van Nood E, van Hoorn DEC, Boelens PG, van Norren $\mathrm{K}$ and van Leeuwen PAM: Flavonoids: a review of probable mechanisms of action and potential applications. Am J Clin Nutr 2001; 74: 418-25.

52. Hirano R, Sasamoto W, Matsumoto A, Itakura H, Igarashi $\mathrm{O}$ and Kondo K: Antioxidant ability of various flavonoids against DPPH radicals and LDL oxidation. J Nutr Sci Vitaminol (Tokyo) 2001; 47: 357-362.

53. Heim KE, Tagliaferro AR and Bobilya DJ: Flavonoid antioxidants: chemistry, metabolism and structure-activity relationships. J Nutr Biochem 2002; 13: 572-584.

54. Cos P, Ying L, Calomme M, Hu JP, Cimanga $\mathrm{K}$ and Van Poel B: Structure-activity relationship and classification of flavonoids as inhibitors of xanthine oxidase and superoxide scavengers. J Nat Prod 1998; 61: 71-6.

55. van Acker SA, Tromp MN,. Haenen GR, van der Vijgh WJ and Bast A: Flavonoids as scavengers of nitric oxide radical. Biochem Biophys Res Commun 1995; 214: 755759.

56. Ferrali M, Signorini C, Caciotti B, Sugherini L, Ciccoli L and Giachetti D: Protection against oxidative damage of erythrocyte membranes by the flavonoid quercetin and its relation to iron chelating activity. FEBS Lett 1997; 416: 123-9.

57. Yeh SL, Wang WY, Huang $\mathrm{CH}$ and Hu ML: Pro-oxidative effect of $\beta$-carotene and the interaction with flavonoids on UVA-induced DNA strand breaks in mouse fibroblast C3H10T1/2 cells. J Nutr Biochem 2005; 16: 729-35.

58. Cao G, Sofic E and Prior RL: Antioxidant and prooxidant behavior of flavonoids: structure-activity relationships. Free Radical Biology and Medicine 1997; 22(5): 749-60.

59. Ramchoun M, Harnafi H, Alem C, Benlys M, Elrhaffari L and Amrani S: Study on antioxidant and hypolipidemic effects of polyphenol-rich extract from Thymus vulgaris and Lavendula multifida. Pharmacognosy Research 2009; 1: 106-112.

60. Pan MH, Lai CS and Ho CT: Anti-inflammatory activity of natural dietary flavonoids. Food and Function 2010; 1(1): 15-31.

61. Mishra A, Kumar S and Pandey AK: Scientific validation of the medicinal efficacy of Tinospora cordifolia. The Scientific World Journal 2013; Article ID 292934: 8.
62. Mishra A, Sharma AK, Kumar S, Saxena AK and Pandey AK: Bauhinia variegata leaf extracts exhibit considerable antibacterial, antioxidant and anticancer activities. BioMed Research International 2013; Article ID 915436: 10.

63. Mishra A, Kumar S, Bhargava A, Sharma B and Pandey AK: Studies on in-vitro antioxidant and antistaphylococcal activities of some important medicinal plants. Cellular and Molecular Biology 2011; 57(1): 16-25.

64. Pandey AK, Mishra AK, Mishra A, Kumar S and Chandra A: Therapeutic potential of $C$. zeylanicum extracts: an antifungal and antioxidant perspective. International Journal of Biological and Medical Research 2010; 1: 228233.

65. Cushnie TPT and Lamb AJ: Antimicrobial activity of flavonoids. International Journal of Antimicrobial Agents 2005; 26(5): 343-56.

66. Cowan MM: Plant products as antimicrobial agents. Clinical Microbiology Reviews 1999; 12(4): 564-82.

67. Mishra AK, Mishra A, Kehri HK, Sharma B and Pandey AK: Inhibitory activity of Indian spice plant Cinnamomum zeylanicum extracts against Alternaria solani and Curvularia lunata, the pathogenic dematiaceous moulds. Annals of Clinical Microbiology and Antimicrobials 2009; 8: 9.

68. Gerdin B and Srensso E: Inhibitory effect of the flavonoid on increased microvascular permeability induced by various agents in rat skin. International Journal of Microcirculation, Clinical and Experimental 1983; 2(1): 39-46.

69. Zandi K, Teoh BT, Sam SS, Wong PF, Mustafa MR and Abubakar S: Antiviral activity of four types of bioflavonoid against dengue virus type-2. Vir Jour 2011; 8: 560 .

70. Namiki M: Antioxidants/antimutagens in food. Critical Reviews in Food Science and Nutrition 1990; 29(4): 273 300.

71. Nagendra Prasad K, Xie H and Hao J: Antioxidant and anticancer activities of 8-hydroxypsoralen isolated from wampee [Clausena lansium (Lour.) Skeels] peel. Food Chemistry 2010; 118(1): 62-66.

\section{How to cite this article:}

Karak P: Biological activities of flavonoids: an overview. Int J Pharm Sci \& Res 2019; 10(4): 1567-74. doi: 10.13040/IJPSR.0975-8232. 10(4).1567-74.

All $\odot 2013$ are reserved by International Journal of Pharmaceutical Sciences and Research. This Journal licensed under a Creative Commons Attribution-NonCommercial-ShareAlike 3.0 Unported License.

This article can be downloaded to Android OS based mobile. Scan QR Code using Code/Bar Scanner from your mobile. (Scanners are available on Google Play store) 